\title{
A Clinical Study of Negative Pressure Wound Therapy (NPWT) in Initial Wound Healing Following Surgical Debridement in Diabetic Wound Infections (DFI) - An Original Research Paper
}

\author{
Raghav Garg ${ }^{1}$, T. Lirangla Sangtam ${ }^{2}$, Ratnakar Namdeo ${ }^{3}$, A.S Chawla ${ }^{4}$ \\ Vardhman Mahavir Medical college \& Safdarjung Hospital, New Delhi ,110029, India
}

\begin{abstract}
Background: A complicated diabetic wound infection, in all its variation; is a common clinical entitywe face in our surgical practice which requires multidisciplinary tailored approach withadequate surgical debridement and antibiotic. This study was conducted in an attempt to assess the efficacy of Negative Pressure Wound Therapy (NPWT) following standard sequence of surgical debridement, antibiotics \& simultaneous optimization of markers of wound healing in patients presenting with moderate and severe diabetic foot infections. Aim: To study the efficacy and safety of Negative Pressure Wound Therapy (NPWT) as an adjunct in the initial wound healing of diabetic foot infections subjected to surgical debridement after 8 weeks of topical therapy. Materials and methods: A total of 30 patients with moderate and severe diabetic foot infections were included in the study, which was conducted in the department of Surgery at Vardhman Mahavir Medical College and Safdarjung Hospital, New Delhi.Results: In our study,all the patients with severe diabetic foot infections showed slow growth of granulation tissue in the first four weeks after surgical debridement alone with antibiotics, while having exponential growth in last 4 to 8 weeks due to NPWT along with serialdebridements. Conclusion: our study concluded that NPWT can be recommended as a useful adjunct to surgical debridement in acutely infected, deep and necrotizing foot infections in diabetics in view of its outcome measures; such as ease of wound management, cost effectiveness and clinical efficacy in wound healing and safety.
\end{abstract}

Keywords: Negative pressure wound therapy (NPWT), VAC therapy, Diabetic foot ulcers

\section{Introduction}

Diabetic foot infection, which is a frequently encountered clinical entity in our surgical practice, presents invariably as deep plantar abscess, wet gangrene and necrotizing fasciitis; which requires admission, medical stabilization, surgical debridement and appropriate antibiotic therapy [1]. Further evaluation for foot sensations, perfusion and presence of associated osteomyelitis or septic arthritis is necessary for tailored approach in a diabetic patient for appropriate local wound therapy and overall limb salvage $[1,2]$.

Although themainstay in the management of diabetic foot infections is adequate surgical debridement with appropriate antibiotics and meticulous wound monitoring,the large exuding wound surfacecreated surgically, usually takes long in the formation of granulation tissue and healing due to range of pathologic abnormalities that exist among the diabetics[3].

Negative Pressure Wound Therapy (NPWT) as a facilitator in creating an ideal wound healing environment through several putative mechanisms [4,5] has been a breakthrough in management of such complex and difficult wounds by enhancing rapid wound bed granulation - a foundation for complete wound closure spontaneously or surgically.

Though much have been written in the literature regarding the use of topical wound therapy such as advanced moist wound therapy(AMWT) using alginate and silver gauge dressings, only limited studies are donein the developing part of the worldusing NPWT as an adjunct in the initial wound healing of infected diabetic wounds. Hence, this study was done to fill the lacuna in the current literature regarding the use ofNegative pressure wound therapy (NPWT) in moderate and severe diabetic foot infections.

\section{Aims and Objectives}

To study the efficacy and safety of Negative Pressure Wound Therapy (NPWT) as an adjunct in the initial wound healing of diabetic foot infections subjected to surgical debridement after 8 weeks of topical therapy by determining:-

- The time of first appearance ofwound bed granulation and progress during 8 weeks of topical therapy.

- The percentage of reduction in wound size at the end of 8 weeks of topical therapy.

- Time for clearance of infection using weekly swab culture sensitivity.

- Incidence of wound related morbidities such as bleeding, maceration, resistant infections or digital gangrene.

\section{Materials and Methods}

Patients selection: The proposed study was conducted in the Department of Surgery at Vardhman Mahavir Medical College and Safdarjung Hospital, New Delhi.

No. of cases: 30 cases of Diabetic patients with moderate and severediabetic foot Infections

Study design: Cross-sectional observational study 


\section{International Journal of Science and Research (IJSR) \\ ISSN (Online): 2319-7064}

Index Copernicus Value (2015): 78.96 | Impact Factor (2015): 6.391

\section{Inclusion criteria:}

Patients more than 12 years of age, clinically diagnosed and staged as having moderate and severe diabetic foot infections (IWGDF classification[2] grade 3 \& 4 or University of Texas classification[101]- 2B \& 3B) after being subjected to surgical debridement and antibiotic coveragewere included in the study.

\section{Exclusion criteria}

- Pregnant or lactating patients.

- Immunosupressive illness and/or therapy.

- severeVenous or arterial insufficiency on clinical examination \& imaging*

- Mid \&/or hindfoot osteomyelitis or septic arthritis on clinical examination \& imaging.

- Crepitus or Soft tissue gas gangrene on clinical examination \& imaging.

(*Patients with Severe arterial insufficiency based on clinical criteria of absence of distal pulses, Capillary flow of $<2 \mathrm{sec}$ or color flow and monophasic waveform on CDFI of popliteal and tibial arteries.)

\section{Observations and Results}

A total of 30 patients presenting to VMMC \& SJH with diabetic foot infections as per inclusion criteria were studied and results evaluated are listed below :-

1) Distribution of grading: According to IWGDF/ University of Texas classification system

In our study $66.67 \%$ of patients were grade 3 while $33.33 \%$ patients were of grade 4 diabetic foot infection according to IWGDF classification.

2) Distribution of Doppler study

In our study $93.33 \%$ patients were having normal color Doppler study while $6.67 \%$ patients were having mild arterial insufficiency on color Doppler.

\section{3) Number of debridement required}

In our study of 30 patients, multiple debridements were done in most of the patients.

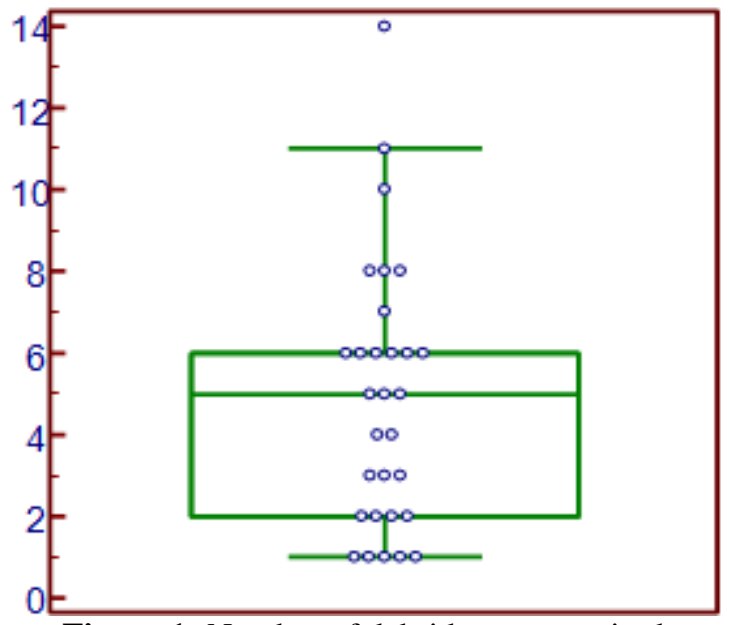

Figure 1: Number of debridement required

In our study of 30 patients, average number of debridement required was 5, standard deviation is $4.9 \pm 3.26$ and interquartile range is $2-6$.

Table 1

\begin{tabular}{|c|c|c|c|c|}
\hline Sample size & Mean \pm St Dev & Median & Min-max & $\begin{array}{c}\text { Interquartile } \\
\text { range }\end{array}$ \\
\hline 30 & $4.9 \pm 3.26$ & 5 & 14-Jan & $2-6$ \\
\hline
\end{tabular}

\section{4) Time for clearance of infection}

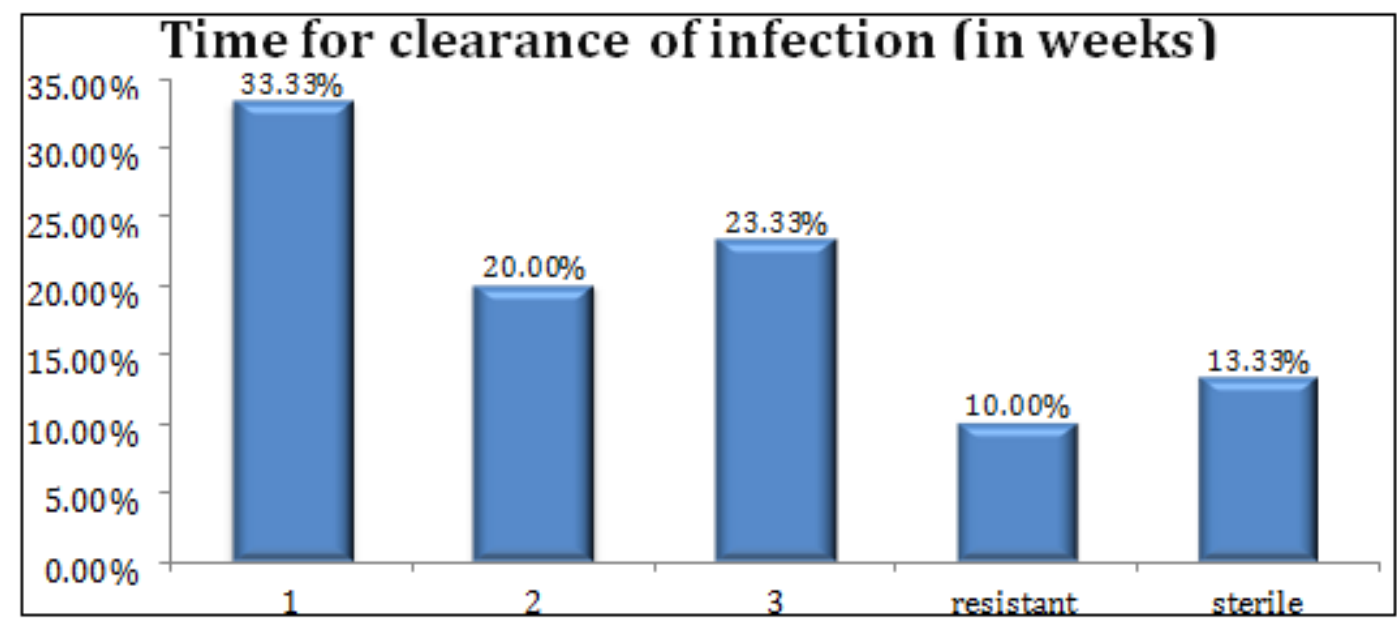

Figure 2: Time for clearance of infection

In our study of 30 patients, 10 patients were clear of infection by the end of $1^{\text {st }}$ week, 6 patients did not show growth of bacteria by the end of $2^{\text {nd }}$ week while 7 patients were also free from infection by the end of $3^{\text {rd }}$ week.
Table 2

\begin{tabular}{|c|c|c|}
\hline & Frequency & Percentage \\
\hline $1^{\text {st }}$ week & 10 & $33.33 \%$ \\
\hline $2^{\text {nd }}$ week & 6 & $20.00 \%$ \\
\hline $3^{\text {rd }}$ week & 7 & $23.33 \%$ \\
\hline Sterile & 3 & $10.00 \%$ \\
\hline Resistant & 4 & $13.33 \%$ \\
\hline Total & 30 & $100 \%$ \\
\hline
\end{tabular}




\section{International Journal of Science and Research (IJSR) \\ ISSN (Online): 2319-7064}

Index Copernicus Value (2015): 78.96 | Impact Factor (2015): 6.391

The average time of clearance of infection was 2 weeks while standard deviation was $1.87 \pm 0.87$ and interquartile range was 1-3 weeks.

Table 3

\begin{tabular}{|c|c|c|c|c|c|}
\hline & $\begin{array}{c}\text { Sample } \\
\text { size }\end{array}$ & Mean \pm Stdev & Median & $\begin{array}{c}\text { Min- } \\
\text { max }\end{array}$ & $\begin{array}{c}\text { Interquartile } \\
\text { range }\end{array}$ \\
\hline $\begin{array}{c}\text { Time to } \\
\text { clearance of } \\
\text { infection } \\
\text { (weeks) }\end{array}$ & 23 & $1.87 \pm 0.87$ & 2 & 3-Jan & $3-3$ \\
\hline
\end{tabular}

\section{5) First appearance of granulation tissue}

In our study, average duration for appearance of granulation tissue was 6.5 days, which is comparable to some studies. Most patients had first appearance of granulation tissue between 5-8 days of negative pressure wound therapy.

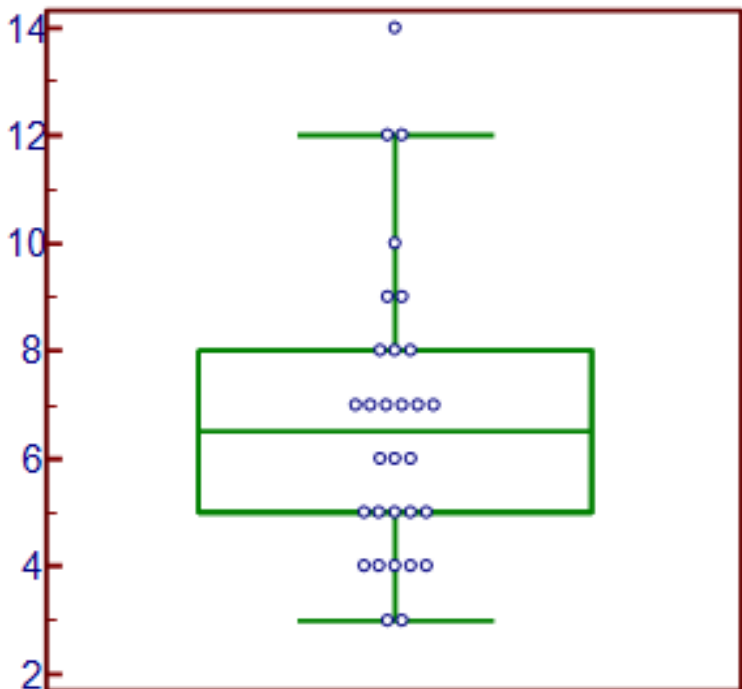

Figure 3: First appearance of granulation tissue

\section{6) Bacteriological culture}

In our study group,weekly culture swabs were taken in which 4 patients showed no growth of bacteria, 2 had growth of acenitobacterbaumanni, 3 patients positive for klebsiella, 4 patients had mixed culture ( $>=2$ organisms), 11 patients had staphylococcus aureus cultures, while 3 patients demonstrated streptococcus in the cultures.

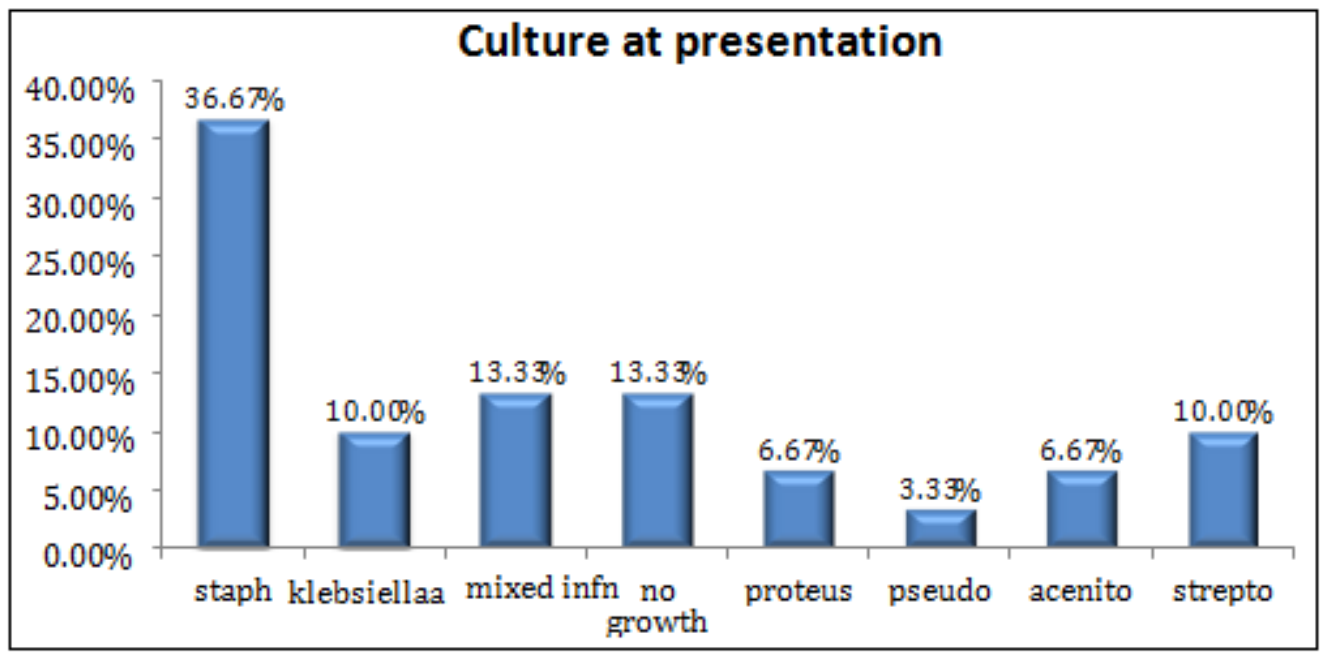

Figure 4: Culture at presentation

Table 4

\begin{tabular}{|c|c|c|}
\hline mixed infection & 4 & $13.33 \%$ \\
\hline No growth & 4 & $13.33 \%$ \\
\hline proteus & 2 & $6.67 \%$ \\
\hline pseudomonas & 1 & $3.33 \%$ \\
\hline klebsiella & 3 & $10.00 \%$ \\
\hline staphlococcus & 11 & $36.67 \%$ \\
\hline streptococcus & 3 & $10.00 \%$ \\
\hline Acenitobacter & 2 & $6.67 \%$ \\
\hline Total & 30 & $100.00 \%$ \\
\hline
\end{tabular}

\section{7) Wound bed and granulation size}

In our study of 30 patients, there was slow growth of granulation tissue in initial 4 weeks and then exponential growth in 4-8 weeks, this is depicted in the graph shown below. 


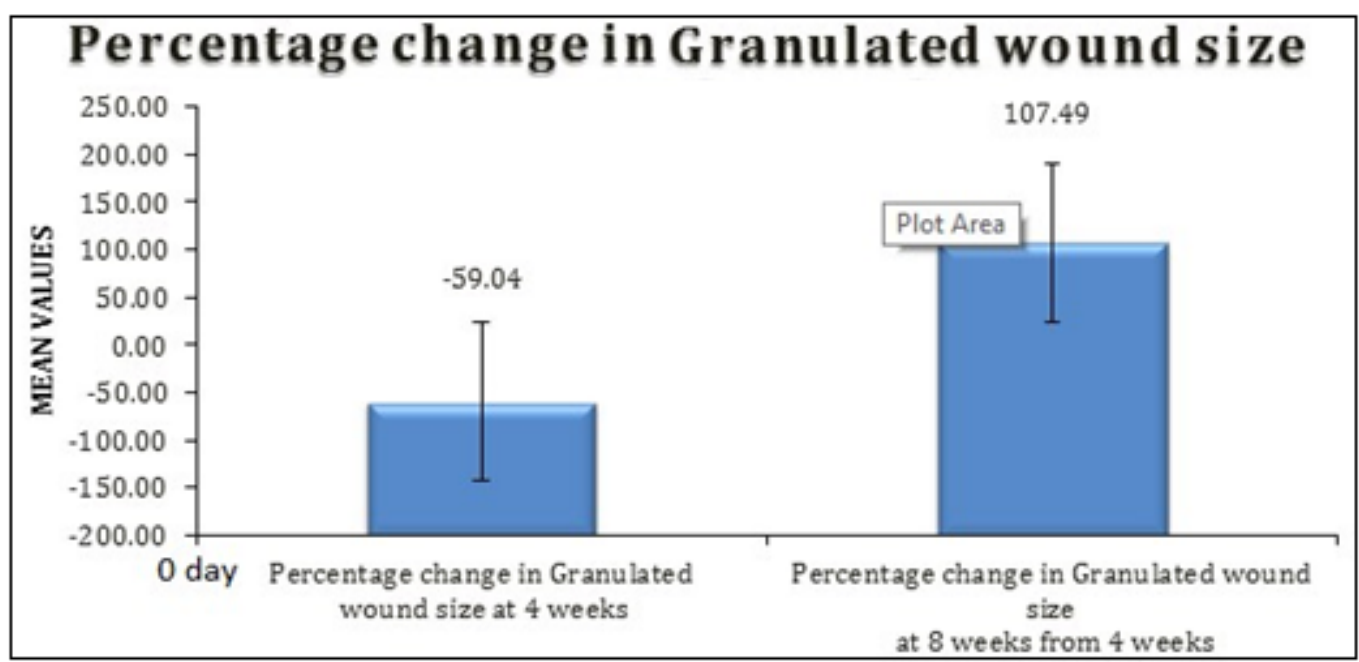

Figure 5: Graph depicting the clinical course of granulation formation over 8 weeks of NPWT

In our study of 30 patients, median change in granulated wound size from 0 to 4 weeks is -60.3 while from 4 to 8 weeks is 101.14 .

Table 5

\begin{tabular}{|c|c|c|c|c|c|}
\hline & Sample size & Mean \pm Stdev & Median & Minmax & Interquartile range \\
\hline $\begin{array}{c}\text { Percentage change in Granulated wound size } \\
\text { at 4 weeks }\end{array}$ & 30 & $-59.04 \pm 10.3$ & -60.3 & $-80-36.36$ & $-66.667--53.333$ \\
\hline $\begin{array}{c}\text { Percentage change in Granulated wound size } \\
\text { at 8 weeks from 4 weeks }\end{array}$ & 30 & $107.49 \pm 55.26$ & 101.14 & $17.65-300$ & $79.167-130.769$ \\
\hline
\end{tabular}

Wound size after initial debridement and granulation wound size over 8 weeks

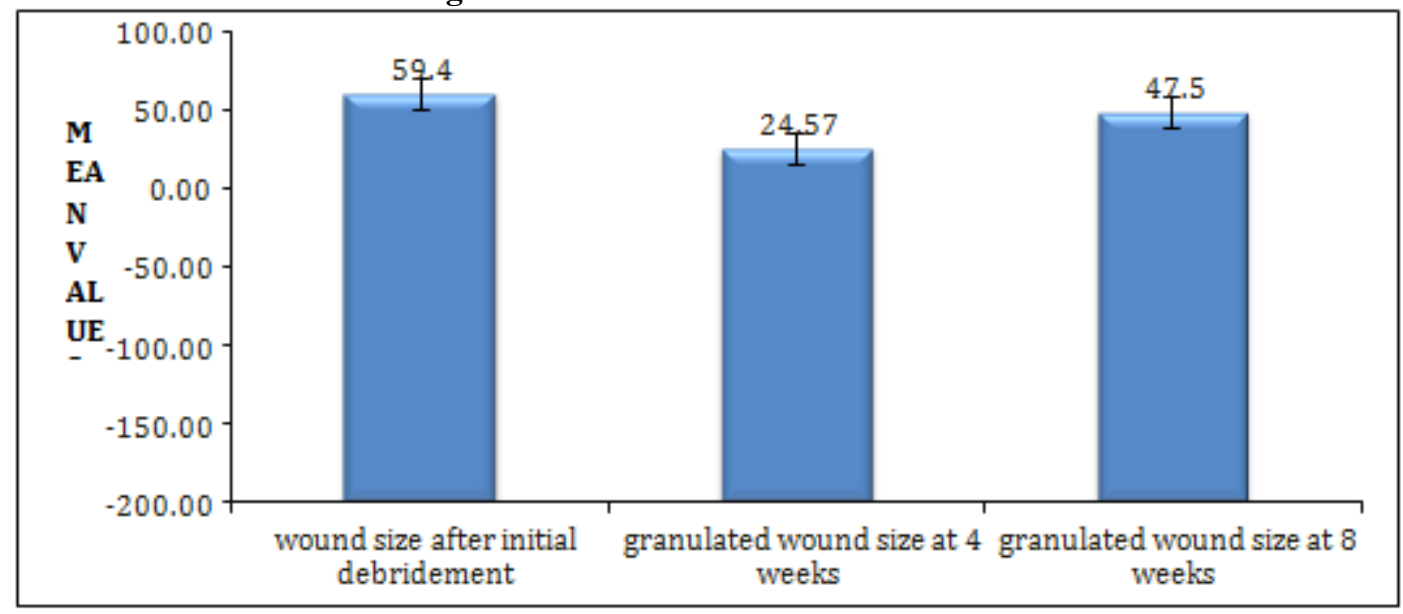

Figure 6: Wound size at different weeks

In our study of 30 patients, mean wound size after initial debridement is $59.4 \mathrm{~cm}^{2}$, while mean granulated wound size after 4 weeks of NPWT is $24.57 \mathrm{~cm}^{2}$ and at 8 weeks is 47.5 $\mathrm{cm}^{2}$. $\mathrm{P}<.0001$ when wound granulated wound size at 4 weeks is compared with granulated wound size at 8 weeks.

Table 6

\begin{tabular}{|c|c|c|c|c|c|}
\hline & Sample & Mean \pm Stdev & Median & Min-max & Interquartile range \\
\hline Wound size after initial debridement & 30 & $59.4 \pm 36.26$ & 55 & $7-124$ & $21-94$ \\
\hline Granulated wound size at 4 weeks & 30 & $24.57 \pm 16.09$ & 22 & Mar-60 & Aug-38 \\
\hline Granulated wound size at 8 weeks & 30 & $47.5 \pm 28.53$ & 47 & Jun-89 & $18-72$ \\
\hline
\end{tabular}




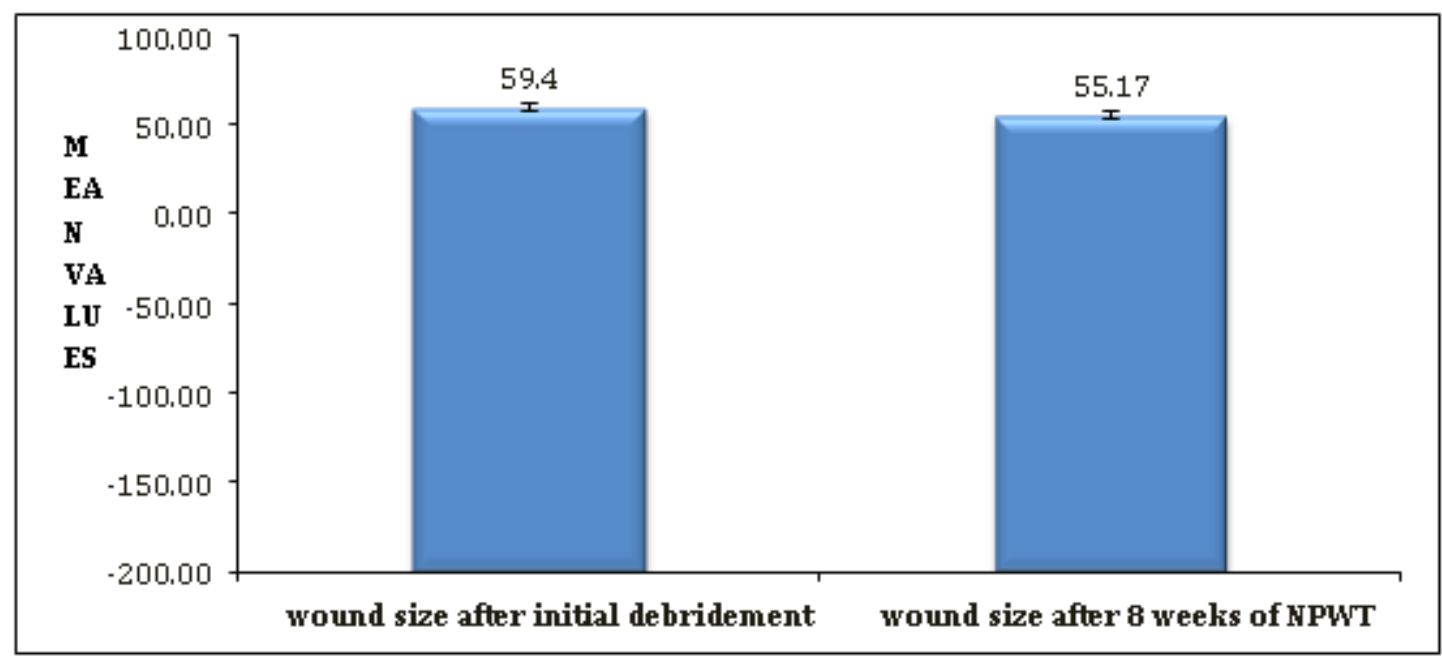

Figure 7: Percentage change in total wound size at the start of NPWT and at 8 weeks .

In our study of 30 patients mean wound size at the start of NPWT or after initial debridement is $59.4 \mathrm{~cm}^{2}$ while wound size after 8 weeks of NPWT is $55.17 \mathrm{~cm}^{2}$. Comparison between the wound sizes is significant as p value is <.0001. Wound contraction is minimal at the end of 8 weeks of NPWT.

Table 7

\begin{tabular}{|c|c|c|c|c|c|c|}
\hline & Sample size & Mean \pm Stdev & Median & Minmax & Interquartile range & $\mathrm{P}$ value \\
\hline Wound size after initial debridement & 30 & $59.4 \pm 36.26$ & 55 & $7-124$ & $21-94$ & \\
\hline Wound size after 8 weeks of NPWT & 30 & $55.17 \pm 34.49$ & 50 & $6-120$ & $20-88$ & $<.0001$ \\
\hline
\end{tabular}

\section{Periwound morbidities}

In our study of 30 patients 6 patients (20\%) were having various periwound morbidities like gangrene of toes, maceration of skin and bleeding from the wound.

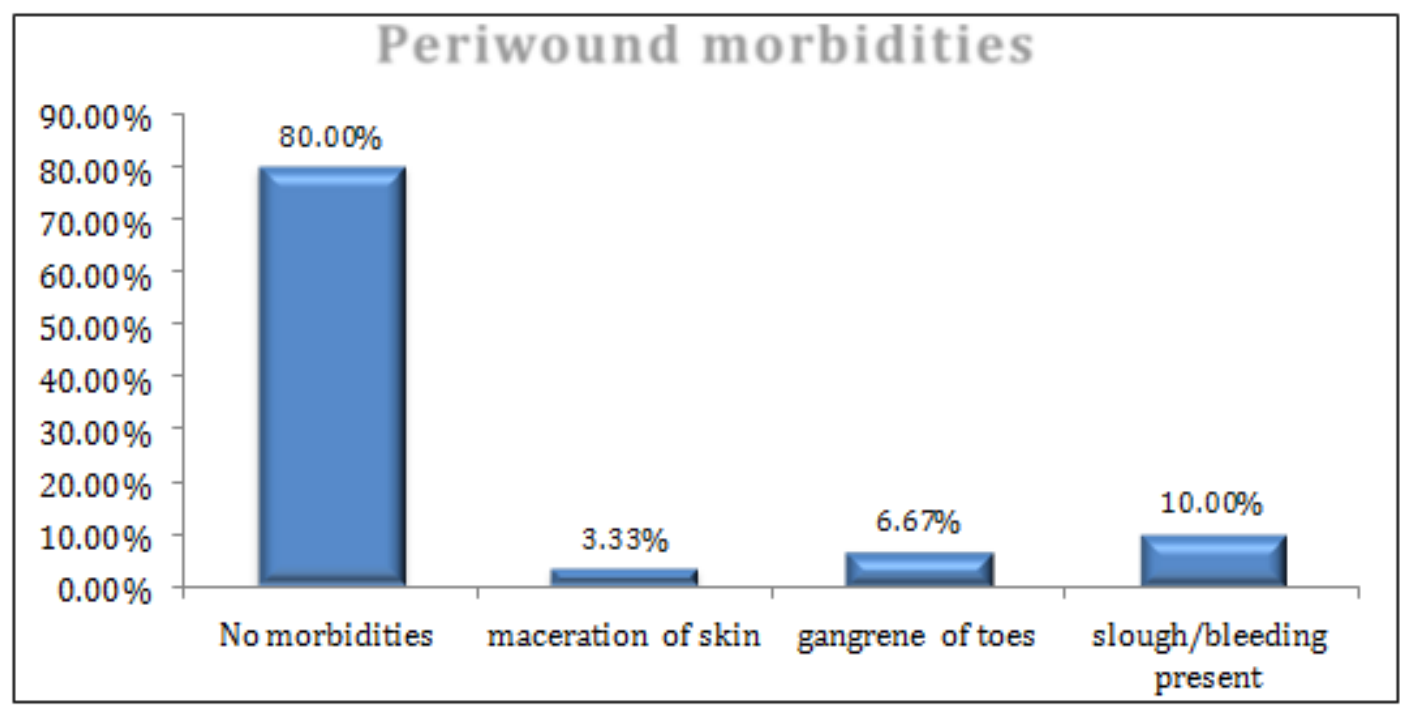

Figure 9: Graph showing periwound morbidities

\section{Discussion}

Negative Pressure Wound Therapy (NPWT) was introduced by Morykwas and Argenta in 1997 which involves application of continuous or intermittent negative pressure on a sealed wound with either foam or gauze ${ }^{[6]}$. This is based on the principle of mechanical stretching of cells which was shown to increase mitosis by Brunette in an experimental study with epithelial cells ${ }^{[7]}$. Further experimental and clinical studies on NPWT have elucidated and validated the mechanisms by which wound healing is improved. Mechanisms of action of NPWT

\section{A. Macro and micro deformation which increase cell proliferation.}

Stress induced by the negative pressure applied through the foam or gauze dressing during NPWT therapy produces a three-dimensional stress within the cells (microstrain) as well as across the whole area of the wound (macro-strain) ${ }^{[8]}$.

Most tissues are viscoelastic and deform slowly over time with applied mechanical forces ${ }^{[9]}$. However, in addition to flow of stretched tissue, these same applied forces also result in an increase in the mitotic rate of the stretched cells ${ }^{[10]}$. 


\section{International Journal of Science and Research (IJSR) \\ ISSN (Online): 2319-7064 \\ Index Copernicus Value (2015): 78.96 | Impact Factor (2015): 6.391}

Macro deformation pulls the periwound area into the wound and encourages wound contraction.

This cell deformation (micro-deformation) has been shown to cause a wide variety of molecular responses, including changes in ion concentration and permeability of membrane ion channels, release of second messengers, stimulation of molecular pathways, and alterations in gene expression ${ }^{[8]}$. Chen et al showed that mechanical shear stresses can activate the vascular endothelial cell growth factor (VEGF) pathway without any VEGF being present in the culture fluid ${ }^{[11]}$. Similar in vivo studies examining both acute wounds in swine and chronic wounds in humans reported an increase in several proto-oncogenes; including myc, c-jun, and Bcl-2, in both wound populations after NPWT application $^{[12]}$.

Thus, it appears that applied mechanical forces deform tissues, which results in deformation of cells; this is followed by stimulation of growth factor pathways, resulting in increased mitosis and production of new tissue (faster wound granulation).

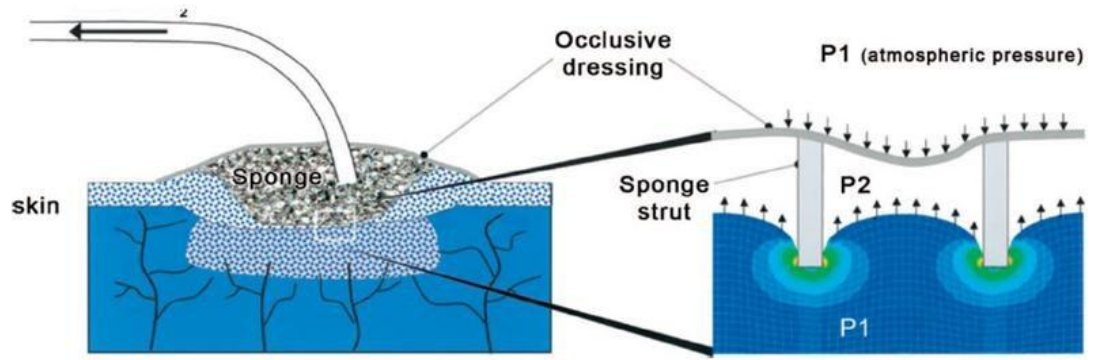

Figure 10: Schematic depiction of NPWT device applied to a wound, overlying adhesive drape that forms a seal, connecting tube, vacuum source, and interface material. The direction of the deforming forces is shown by arrows. Reprinted from Saxena et al. ${ }^{[8]}$

\section{B. Increasing wound perfusion.}

Multiple studies have reported the positive effects NPWT has on tissue perfusion ${ }^{[13]}$. Morykwas et al in a series of studies using wounds in a pig model that were subjected to NPWT observed that Doppler measured blood flow levels increased fourfold when $125 \mathrm{mmHg}$ negative pressure was applied to the wounds. The survival of random pattern flaps was significantly increased $(\mathrm{P}=0.05)$ by $21 \%$ compared with controls.

Wackenfors et al. recorded an increase in blood flow with 60 minutes of NPWT therapy accompanied with enhanced wound fluid partial pressures of oxygen and lactate. The combination of oxygen and lactate is known to promote wound healing [14].

\section{Exudate Removal and Edema Reduction}

It has been shown that fluid from chronic wounds contains abnormally high proteases such as matrix metalloproteinases (MMPs), elastase, plasmin and thrombin ${ }^{[15]}$. Excessive protease activity in chronic wounds results in abnormal degradation of the extracellular matrix, negatively impacting wound healing ${ }^{[16]}$. NPWT continuously removes the exudative fluid while keeping the wound moist.

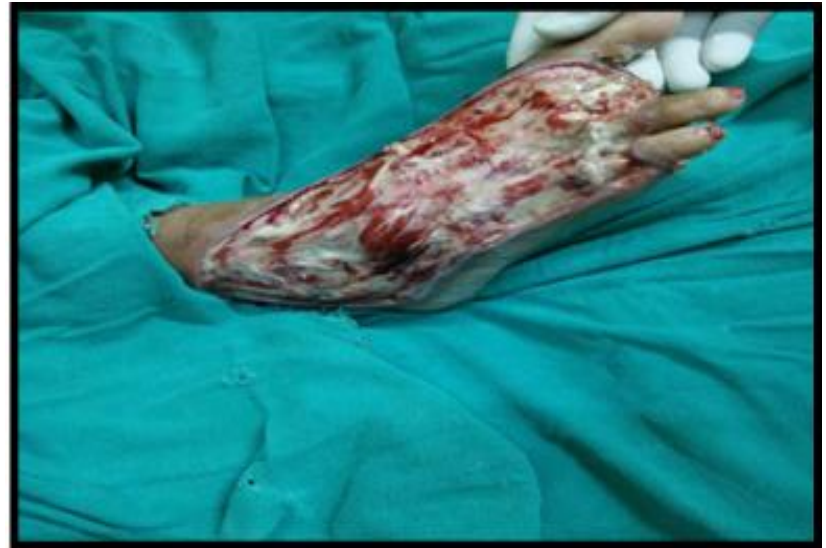

Photograph (a) Wound after first radical surgical debridement

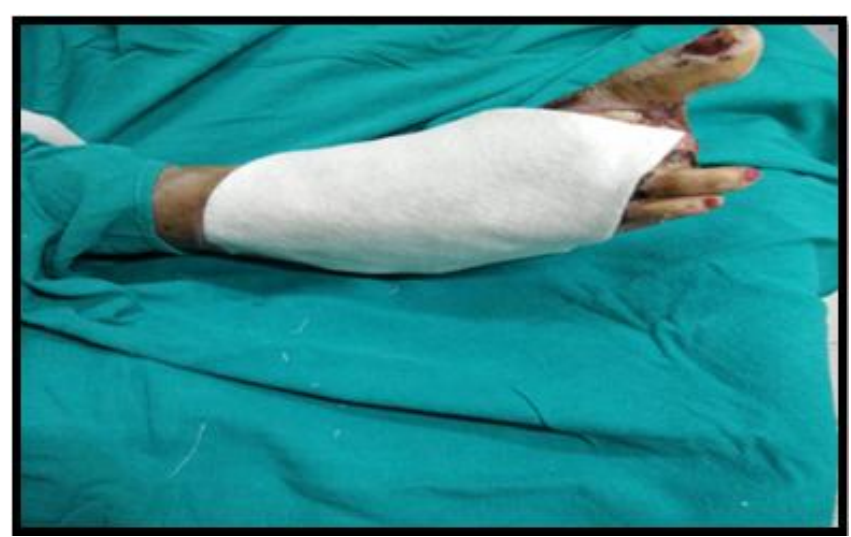

Photograph (b) Wound covered with gauge piece after surgical debridement preparing for application of indigenously made NPWT 


\section{International Journal of Science and Research (IJSR)

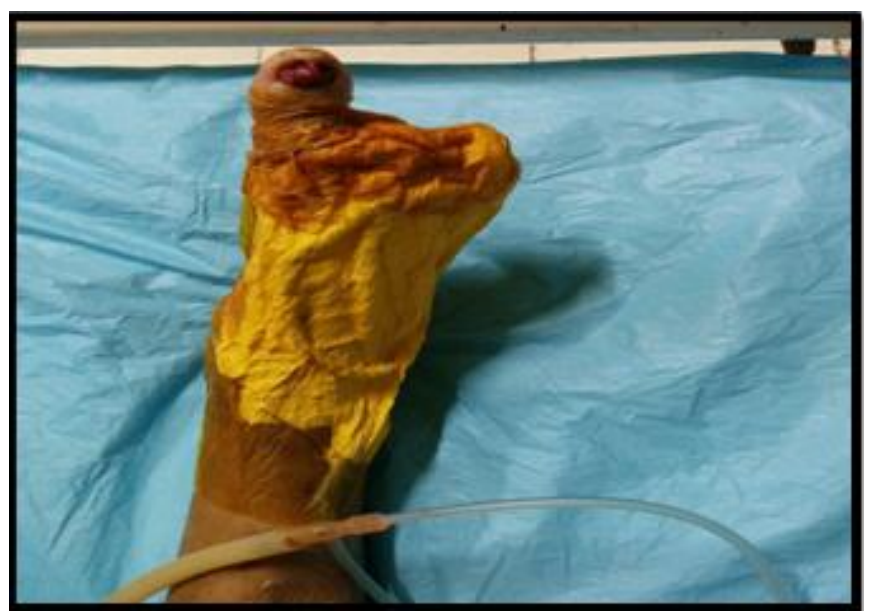

Photograph (c) Showing application of Negative Pressure Wound Therapy

\section{Change in the expression of biomarkers in chronic wounds}

Shi et al. studied the changes in MMPs in chronic wounds after treatment with NPWT by quantifying the expression of messenger RNA encoding these proteins ${ }^{[17]}$. They reported a steep decrease in MMPs similar to findings in a study by Moues et al ${ }^{[18]}$

In our study of 30 subjects, we found that percentage change in granulated wound size at weeks is 59.04 while percentage change in granulated wound size at 8 weeks from 4 weeks is 107.49. we also observed that mean wound size after initial debridement is $59.4 \mathrm{~cm}^{2}$, mean granulated wound size at 4 weeks is $24.57 \mathrm{~cm}^{2}$ while mean granulated wound size at 8 weeks is $47.5 \mathrm{~cm}^{2}$. Percentage change in granulated wound size at 8 weeks from 4 weeks is statistically significant as p $<.0001$. Cardinal \& Sheehan in their study had $50 \%$ wound area reduction at 4 weeks while Lavery\&colleagues ${ }^{[19]}$ had $15 \%$ wound area reduction after 1 week and $60 \%$ after 4 weeks of NPWT. Bradbury et al observed $42.64 \%$ decrease in wound area at the end of 8 weeks of NPWT while Aziz Nather et al ${ }^{[20]}$ had $24.9 \%$ average reduction in the end of their study. In our study mean wound size after initial debridement is $59.4 \mathrm{~cm}^{2}$ while mean wound size at the end of 8 weeks of NPWT is $55.17 \mathrm{~cm}^{2}$. Percentage change in wound size at the end of 8 weeks NPWT and the start of NPWT is very less as the wound contraction is minimal by negative pressure wound therapy.

Incidence of wound and periwound related morbidities ,In our study of 30 patients, two patients (6.67\%) had gangrene of toes during NPWT which may be due to mild arterial insufficiency detected on colour Doppler in three patients .One patient $(3.33 \%)$ had periwound maceration which could be attributed to the large size of the wound and IWGDF grade 4.

\section{Conclusion and Recommendations}

The conclusion from our study as regards to our objectives efficacy and safety of negative pressure wound therapy as an adjunct in the setting of severe diabetic foot infection, verifiably conform with the existing studies.
NPWT can therefore likely and should be recommended as the line of care in acutely infected, deep and necrotising foot infections in diabetics in view of its outcome measures such as ease of wound management ( infrequent dressing change and pain-free ambulation ), expense ( as opposed to costly newer generation dressings; slower healing and delayed recovery), effectivity ( complete wound granulation within 8 weeks) and safety (negligible periwound morbidity with minimal interruption of therapy ).

However, multiple on surgical debridements, appropriate antibiotics and optimisation of comorbidities will remain as ever the bedrock over which lies the successful outcome of Negative Pressure Wound Therapy as an adjunct.

\section{References}

[1] Capobianco CM, Stapleton JJ. Diabetic foot infections: A team-oriented review of medical and surgical management. Diabetic foot \& ankle 2010;1:10.3402/dfa.v1i0.5438.doi:10.3402/dfa.v1i0.543 8. Last accessed on September 2, 2015

[2] Lipsky BA, Berendt AR, Cornia PB, Pile JC, Peters EJ, Armstrong DG et al. 2012 Infectious Diseases Society of America clinical practice guideline for the diagnosis and treatment of diabetic foot infections. Clin infect dis 2012;54:132-73.

[3] Nather A, Chionh SB, Han AYY, Chan PPL, Nambiar A. Effectiveness of Vacuum-assisted Closure (VAC) Therapy in the Healing of Chronic Diabetic Foot Ulcers. Ann Acad Med Singapore 2010;39:353-78.

[4] Hasan MY, Teo R, Nather A. Negative-pressure wound therapy for management of diabetic foot wounds: a review of the mechanism of action, clinical applications, and recent developments. Diabetic Foot \& Ankle 2015, 6: 27618 - http://dx.doi.org/10.3402/dfa.v6.27618. Last accessed on September 2, 2015 .

[5] Morykwas MJ, Argenta LC. Nonsurgical modalities to enhance healing and care of soft tissue wounds. J South OrthopAssoc1997;6:279-88.

[6] Morykwas M.J., Argenta L.C., Shelton-Brown Vacuum-assisted closure: A new method for wound control and treatment: Animal studies and basic foundation. Annals of Plastic Surgery. 1997; 38:553562.

[7] Brunette D.M. Mechanical stretching increases the number of epithelial cells synthesizing DNA in culture. Journal of Cell Science. 1984; 69: 35.

[8] Saxena V., Hwang C.W., Huang S. Vacuum-assisted closure: microdeformations of wounds and cell proliferation. Plastic and Reconstructive.

[9] Wilhelmi B.J., Blackwell S J., Mancoll J.S. Creep versus stretch: A review of the viscoelastic properties of skin. Annals of Plastic Surgery. 1998; 41: 215.

[10] Austad E.D., Thomas S.V., and Pasyk K. Tissue expansion: Dividend or loan? Plastic and Reconstructive Surgery. 1986; 78: 63.

[11]Chen K.D., Li Y.S., Kim M. Mechanotransduction in response to shear stress: Roles of receptor tyrosine kinases, integrins, and Shc. The journal of Biological Chemistry. 1999; 274: 18393.

[12] Chen S.Z., Cao D.Y., Li J.Q. Effect of vacuum-assisted closure on the expression of proto-oncogenes and its 


\section{International Journal of Science and Research (IJSR) \\ ISSN (Online): 2319-7064 \\ Index Copernicus Value (2015): 78.96 | Impact Factor (2015): 6.391}

significance during wound healing. Zhonghua Zheng Xing Wai KeZaZhi 2005; 21: 197.

[13] Wackenfors A., Sjogren J., Gustafsson R. Effects of vacuum-assisted closure therapy on inguinal wound edge micro-vascular blood flow. Wound Repair and Regeneration. 2004; 12:600-666.

[14].Hopf H.W., Gibson J.J., Angeles A.P. Hyperoxia and angiogenesis. Wound Repair and Regeneration. 2005; 13:558-64.

[15] Tarnuzzer R.W. and Schultz G.S. Biochemical analysis of acute and chronic wound environments. Wound Repair and Regeneration. 1996; 4:321-5.

[16]Harding K.G., Morris H.L. and Patel G.K. Science, medicine and the future: healing chronic wounds [Review]. British Medical Journal. 2002; 324:160-3. Shi B., Chen S.Z., Zhang P. Effects of vacuum assisted closure (VAC) on the expressions of MMP-1, 2, 13 in human granulation wound. Zhonghua Zheng Xing Wai KeZaZhi. 2003; 19:279-81.

[17] Shi B., Chen S.Z., Zhang P. Effects of vacuum assisted closure (VAC) on the expressions of MMP-1, 2, 13 in human granulation wound. Zhonghua Zheng Xing Wai KeZaZhi. 2003; 19:279-81.

[18] Moues C.M., van Toorenenbergen A.W., Heule F. The role of topical negative pressure in wound repair: Expression of biochemical markers in wound fluid during wound healing. Wound Repair and Regeneration. 2008; 16: 488-494.

[19] Lavery LA, Armstrong DG, Harkles LB: Classification of diabetic foot wounds. J Foot ankle surgery 1996; 53 : 528-531

[20] Nather A, Chionh SB, Han AY, Chan PP, Nambiar A. Effectiveness of vacuum-assisted closure (VAC) therapy in the healing of chronic diabetic foot ulcers. Ann Acad Med Singapore 2010; 39: 353-358. 